\title{
A TRADUÇÃO DOS CLÁSSICOS E O PÓ DAS BIBLIOTECAS
}

\author{
Giorgio de Marchis* \\ Università degli Studi Roma Tre
}

\begin{abstract}
Resumo: $\mathrm{O}$ artigo apresenta uma tradução pouco conhecida de $O$ Primo Basílio publicada na Itália, em 1966, numa coleção popular. A análise de La cugina, além de oferecer mais uma contribuição para a reconstrução da fortuna italiana de Eça de Queirós, procura identificar os mecanismos de manipulação literária que, numa tradução, podem deslocar uma obra do centro do cânone para as margens paraliterárias.
\end{abstract}

Palavras-chaves: Literatura popular. Manipulação. Cânone.

\section{THE CLASSICS TRANSLATIONS, AND THE LIBRARIES DUST}

\begin{abstract}
The article presents a lesser-known translation of $O$ Primo Basílio published in Italy in 1966, as part of a popular collection. The analysis of La cugina, besides offering one more contribution to the reconstruction of the critical fortune of Eça de Queirós, attempts to identify the mechanisms of literary manipulation that, in a translation, can move a literary work from the centre of canon to the paraliterary margins.
\end{abstract}

Keywords: Popular literature. Manipulation. Canon.

\footnotetext{
* Doutorado em Iberística pela Universidade de Bolonha, é professor associado de Literatura portuguesa e brasileira no Departamento de Línguas, Literaturas e Culturas Estrangeiras da Universidade de Roma III. Roma, Itália. E-mail: giorgio.demarchis@uniroma3.it
} 
A fortuna italiana de Eça de Queirós apresenta características peculiares, tanto dum ponto de vista geral e internacional, como no âmbito mais restrito das relações literárias luso-italianas e da recepção na Itália dum escritor português. No primeiro caso, se considerarmos que La reliquia - a primeira tradução queirosiana publicada na Itália - só saiu em 1913, não há dúvida que os leitores italianos tiveram a possibilidade de conhecer este escritor relativamente tarde, tendo em conta, por exemplo, que a primeira tradução alemã de $O$ Primo Basílio aparecera em 1880, a versão francesa do mesmo romance três anos mais tarde, a americana em 1889 e que, apenas dez anos após a morte do autor, todos os seus romances já se encontravam traduzidos em espanhol. Por outro lado, se Eça chega tarde às livrarias italianas, também é verdade que, ao contrário do que se verificou com outros autores seus compatriotas, o interesse para com a sua obra nunca diminuiu, sendo possível alguém afirmar que “(...) em Itália, entre as glórias universais, Eça é um dos autores maiormente traduzidos, e, a sua apoteose, embora alcançada lenta e gradualmente, não conheceu num século nem interrupções nem quedas” (Di Munno, 23).

São diversos os estudos dedicados às traduções italianas do autor de Os Maias e, portanto, não tenciono propor mais uma história da sua recepção na Itália. Limitar-me-ei a apresentar uma tradução de $O$ Primo Basílio que até hoje passou despercebida; trata-se, como se verá, dum episódio secundário, dum acontecimento de pouca ou nenhuma relevância cultural, que, porém, poderá ter algum interesse pela sua capacidade de exemplificar as relações dinâmicas que no sistema literário sempre se estabelecem entre o centro do cânone e as suas margens paraliterárias.

Pelo que concerne ao número das traduções de $\mathrm{O}$ Primo $\mathrm{Ba}$ sílio, as opiniões diferem bastante: no seu Catalogo ragionato degli autori portoghesi tradotti ed editi in Italia, Jaime Raposo Costa refere uma única tradução: a de Bernardo Crippa publicada em 1952 pela editora milanesa Rizzoli. Já Amina Di Munno (e, mais tarde, também Davide Conrieri e Maria Abreu Pinto) fala de duas traduções do romance, lembrando também a versão de Laura 
Marchiori que a editora Mondadori publicou nesse mesmo ano. Porém, como escreve Ernesto Guerra da Cal, Il cugino Basilio, na tradução de Marchiori, já tinha sido publicado, sem introdução, em 1945 com a chancela da editora milanesa - hoje extinta - Perinetti Casoni. ${ }^{1}$

Contudo, além das traduções de Laura Marchiori e Bernardo Crippa, existe também uma terceira versão italiana deste romance que até hoje nunca foi noticiada nos principais estudos bibliográficos dedicados à obra de Eça de Queirós. Em 1966, de facto, na coleção "I romanzi diabolici” dirigida por Ennio Mancini - um dos mais ativos editores de literatura popular na Itália dos anos Sessenta com as chancelas Grandi Edizioni Internazionali e Edizioni Periodici Italiani ${ }^{2}$-, publicou-se uma obra de Eca (sic) de Queiroz com o bem pouco queirosiano título de La cugina.

O livro em questão é apresentado aos leitores como uma libera riduzione de Il cugino Basilio mas não se conhece nem o nome do tradutor (e o texto não parece ser uma manipulação das anteriores versões de Marchiori e Crippa) nem o nome do autor do breve prefácio que apresenta o escritor e a obra. $\mathrm{O}$ único a ter direito a sair do anonimato é o autor da capa - o conhecido pintor de cartazes cinematográficos Angelo Cesselon - que, como se verá, contribui para definir a identidade para-textual dum objecto-livro que apresenta muitas das características da fórmula editorial própria das coleções de literatura popular: o pequeno formato (neste caso $19 \mathrm{x}$ $12 \mathrm{~cm}$ ); o preço muito reduzido (150 liras italianas, na altura, mais ou menos o custo de três jornais e pouco menos do preço dum litro de leite); as marcas para-textuais que inserem o livro numa série (o livro em questão é o número 56 duma coleção, "I romanzi diabólici”, que, entre 1963 e 1967, publicou dois romances por mês distribuídos como periódicos nas bancas de jornais - se bem que existisse a possibilidade de assinaturas anuais ou semestrais, como indica o editor no colofão da publicação).

Pelo que concerne à capa, embora Angelo Cesselon respeite as três funções que se costumam atribuir a este elemento (identificação da obra, definição do seu conteúdo e sua valorização), 
provavelmente, neste caso, poderá ter alguma razão Daniel Couégnas quando afirma que nas últimas décadas a principal função das capas das coleções populares tem sido a de cativar o interesse do leitor, explicitando ao mesmo tempo o caráter "popular" e não "literário" da coleção.

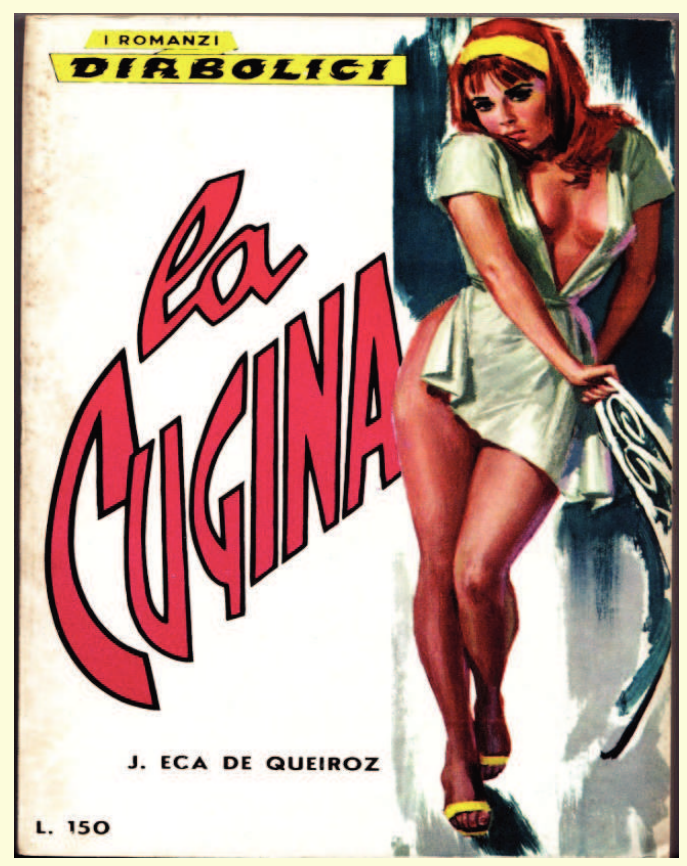

Ilustração 1

Continuando a análise da identidade para-textual desta tradução, é evidente a alteração do título da obra que, nesta versão, desvia a atenção do leitor da personagem do primo Basílio, focalizando-a na figura da prima adúltera Luísa. Uma alteração muito significativa porque, como escreve Manuela Nunes, "O título que Eça deu ao seu romance distingue-o dos outros grandes romances realistas do século XIX que têm o adultério como tema" (650): Madame Bovary, Anna Karenina, e as obras do alemão Thedor Fontane L'adultera, Cécile 
e Effi Briest. Ao contrário, "Não é a adúltera que dá o nome ao romance de Eça e sim o sedutor" (Couégnas, 33). Uma opção, esta de Eça, que, porém, resulta inviável para a coleção dos "romances diabólicos" que se caracteriza por títulos que obedecem a um princípio de imediatismo e explicita sedução, abrindo ao público, o universo obscuro do Desejo, das tentações, dos tabus morais e sociais do potencial leitor com títulos como Le notti oscene, La belva nel letto, Moglie di tutti, Carne inquieta e, porque não, La cugina.

Surpreende numa coleção deste tipo a presença dum prefácio. De facto, as portas de acesso a um texto paraliterário não costumam ser quase nunca obstruídas por formas de metalinguagem como são as epígrafes, as dedicatórias ou qualquer texto limiar. Neste caso, porém, não se pode ignorar que "I romanzi diabolici", mesmo sendo uma coleção popular, propõe aos seus leitores " $i$ grandi narratori" ${ }^{3}$, apresentando-se, por incrível que isso hoje possa parecer, como uma operação de divulgação cultural que reflete as novas condições socioculturais dum país onde cresce o número dos leitores e se afirmam práticas de leitura extensiva ${ }^{4}$.

O prefácio funciona, portanto, como mecanismo de legitimação literária mas, neste caso, propõe também uma interpretação do romance queirosiano bastante duvidosa, ainda que coerente com a apresentação para-textual da obra e com o tom de toda a coleção ${ }^{5}$ :

La cugina Luisa potrebbe ricordarci una Bovary su scala minore... eppure c'è differenza fra l'adultera provinciale francese e lei. La religione, l'ossessione della morte, l'onore sbandierato nei trattenimenti serali la accompagnano senza sosta, fino al letto dell'amante. E il tradimento stesso ha luogo e si snoda in seno alla famiglia, è una cosa che rimane in casa. Per questo tanto più grave ma anche tanto più inevitabile, se si pensa alla solitudine di un temperamento caldo, abbandonato a se stesso e a tutto il suo tempo libero, al languore sensuale dei fados, all'atmosfera di pettegolezzo per cui avere un amante è peccato, non averlo è vergogna. (QUEIROZ, 1966, 4). 
La cugina é, portanto, um típico texto-industrial, um dos inúmeros livros de bolso que, nos anos do boom econômico, se vendiam, com periodicidade variável, nas bancas de jornais (os célebres "Oscar Mondadori", por exemplo, foram lançados em 1965 com tiragens que atingiram, semanal ou mensalmente, os 100.000 exemplares). Uma fórmula editorial nova que, segundo Giovanni Ragone, determinou "l'omologazione - sotto un unico marchio e prezzo - di autori e testi di spessore e autorità totalmente eterogenea" (78), contribuindo, junto a outros factores (a "invenção" do best-seller, o sucesso das estratégias e dos géneros seriais), para mudar definitivamente o mercado do livro na Itália.

No que diz respeito à relação entre $O$ Primo Basílio e La cugina, algumas operações indicam-nos que, além duma evidente trivialização, a tradução obedece a critérios etnocêntricos que procuram pôr um público sem grandes exigências literárias nas condições de leitura mais confortáveis, simplificando o acesso ao texto queirosiano. Deste ponto de vista, a adaptação à época contemporânea é provavelmente um escamotage finalizado a facilitar a fruição dum clássico. Em La cugina encontram-se, assim, telefonemas a substituírem cartas, ar condicionado no hotel de Basílio e Juliana preocupada por ter que fazer um electrocardiograma. Esta estratégia de atualização e simplificação torna-se evidente na descrição do "Paraíso" - o apartamento que Basílio aluga para os seus encontros com Luísa, que deixa de ser uma choça "para os lados de Arroios" coerente com o imaginário romanesco duma leitora de Paul Feval ${ }^{6}$ para se transformar, renunciando a qualquer referência às leituras da adúltera Luísa, numa bem mais simples “(...) casetta alla periferia di Lisbona, uno di quei casolari apparentemente ancora abitati da contadini ma che qualche raffinato ha completamente trasformati all'interno" (Queiroz, 1966, 67-68)

Além de mudar a época dos acontecimentos, esta libérrima redução, organizada em dez capítulos, suprime também grande parte do romance português (mais ou menos $80 \%$ do texto); desaparecem assim muitas personagens (Leopoldina, Julião Zuzarte, Ernesto Ledesma, a tia Vitória, o jornalista Saavedra, o banqueiro 
Castro, o comissário Vicente Azurara, Mariana, o doutor Caminha e todos os vizinhos de Jorge e Luísa) e desaparecem também alguns dos episódios mais significativos da obra, indispensáveis para a definição do discurso ideológico queirosiano (as reconstruções, em analepse, da educação de Luísa, Juliana e Sebastião; quase todos os serões, aos domingos, na casa de Luísa e Jorge, a ida ao Passeio Público de Basílio, Luísa e D. Felicidade, o jantar na casa do conselheiro Acácio, o encontro entre Castro e Luísa na casa de Leopoldina, a morte de Juliana, etc.). É verdade que o mesmo Eça achava no Primo Basílio, como escreve numa carta ao amigo Teófilo Braga, "uma superabundância de detalhes, que obstruem e abafam um pouco a acção" (Queiroz, 2008, 184); o romancista, como é sabido, em Março de 1878, julgava que o seu processo precisava de se simplificar, condensar-se, mas duvido que estivesse a pensar numa operação como a que se realizou quase um século mais tarde com La cugina, quando afirmava a importância de dar a nota justa, "um traço justo e sóbrio" (Queiroz, 2008, 184).

$\mathrm{O}$ anônimo re-escritor italiano, porém, não se limita a suprimir personagens e episódios, acrescenta também um inteiro capítulo que Eça nunca escreveu. De facto, o primeiro capítulo de La cugina apresenta ao leitor Juliana, Luísa e Jorge antes do casamento dos noivos. Nas primeiras páginas desta versão italiana, a tia Virgínia ainda está viva mas a sua relação com o sobrinho é péssima porque Jorge, anos antes, manteve uma escandalosa relação com uma bailarina (tudo isto, evidentemente, Eça nunca o escreveu). Encontra-se viva também a mãe de Luísa, "la signora Rosita", que desconfia de Giuliana e quer que Giorgio recupere o apreço da tia em vista do testamento. Neste primeiro capítulo, finalmente, o leitor é informado que Giuliana mantém clandestinamente relações sexuais com Antonio, uma relação, esta, que n'O Primo Basílio Eça atribui à cozinheira Joana e ao seu amante Pedro, descrevendo-a, porém, em termos muito menos explícitos. ${ }^{7}$

Trata-se, em suma, duma hábil manipulação do texto original finalizada a tornar mais simples a compreensão da obra por parte do público; ou seja, quem organizou La cugina sabia que precisava 
de esclarecer da maneira mais evidente possível tudo o que $O$ Primo Basílio deixa simplesmente subentender aos seus leitores. Nesta ótica, a versão italiana do romance, no segundo capítulo, transcreve também parte do testamento da tia Virginia (inexistente em Eça) para que fique clara a decepção de Giuliana que, com o dinheiro e a casa da "vecchia maledetta" tencionava casar-se com Antonio.

Contudo, mais do que analisar tudo o que desaparece ou é acrescentado ao romance queirosiano nesta sua invulgar tradução, a pergunta mais estimulante poderá ser: porque é que alguém fez isto? Quais fins e que poética determinaram a estratégia deste tradutor, levando-o a alterar tão profundamente o original (original que, se calhar, o anônimo manipulador nem sequer chegou a ler)?

Para tentar responder a estas perguntas, muito útil poderá revelar-se a análise de duas passagens bastante significativas de $O$ Primo Basílio - o parágrafo inicial do romance queirosiano e uma das cenas mais ousadas e criticadas da obra. No primeiro caso, Eça descreve nestes termos uma típica situação doméstica:

Tinham dado onze horas no «cuco» da sala de jantar. Jorge fechou o volume de Luiz Figuier que estivera folheando devagar, estirado na velha voltaire de marroquim escuro, espreguiçou-se, bocejou e disse: / - Tu não te vais vestir, Luiza? / - Logo. / Ficara sentada à mesa, a ler o «Diário de Notícias». Roupão de manhã de fazenda preta, bordado a soutache, com largos botões de madrepérola; o cabelo louro um pouco desmanchado, com um toco seco do calor do travesseiro, enrolava-se, torcido no alto da cabeça pequenina, de perfil bonito; a sua pele tinha a brancura tenra e láctea das louras: com o cotovelo encostado à mesa acariciava a orelha, e, no movimento lento e suave dos seus dedos, dois anéis de rubis miudinhos davam cintilações escarlates. / Tinham acabado de almoçar. (QUEIROZ, 1878, 11).

As versões de Laura Marchiori e Bernardo Crippa, ainda que com algumas diferenças, não se distanciam muito da proposta quei- 
rosiana. Limito-me, por enquanto, a evidenciar como a proposta de Crippa seja ligeiramente mais pudica (o movimento dos dedos é aqui lento e suave e não é a pele a ter a brancura "tenra e láctea das louras" mas apenas o rosto da mulher):

Il cucú della stanza da pranzo aveva suonato le undici. Giorgio chiuse il volume di Louis Figuier che aveva sfogliato lentamente, sdraiato sulla vecchia poltrona di cuoio scuro, si stirò, sbadigliò e disse: / - Non vai a vestirti, Luisa? / Fra poco / Era rimasta seduta a tavola a leggere il Diário de Notícias: indossava una vestaglia di stoffa nera con guarnizioni di cordoncino e grandi bottoni di madreperla; $i$ capelli biondi un po' arruffati, inariditi dal tepore del guanciale, si attorcigliavano in cima alla testa piccolina, dal profilo grazioso; la sua carnagione aveva la bianchezza delicata e lattea delle bionde; col gomito appoggiato alla tavola si accarezzava l'orecchio, e, nel movimento lento e morbido delle dita, due anelli con piccoli rubini sprizzavano scintillii vermigli. / Avevano finito di far colazione. (QUEIROZ, 1952, 17).

Erano suonate le undici al cucù della sala da pranzo. / Giorgio sdraiato nella vecchia voltaire di marocchino scuro, chiuse il libro di Luigi Figuier che stava lentamente sfogliando, si stirò, sbadigliò e disse: / - Luisa, non ti vai a vestire? / - Subito. / E rimase seduta al tavolo intenta a leggere il Diario de Noticias. Era in veste da camera, nella solita vestaglia di stoffa nera dai grandi bottoni di madreperla, ricamata in soutache; $i$ suoi capelli, un poco in disordine e secchi per il caldo del cuscino, si inanellavano raccolti sulla testolina dal profilo grazioso: il viso mostrava il tenero e niveo candore proprio delle bionde. Con il gomito appoggiato al tavolo si accarezzava un orecchio e, nel movimento lento e soave delle dita, due anelli dai minuscoli rubini mandavano scintillii scarlatti. / Avevano terminato di far colazione. (QUEIROZ, 1952, 17). 
Muito diferente a tradução publicada em 1966:

Erano suonate le undici al pendolo del salotto. Giorgio, sdraiato sulla Voltaire che era stata del povero zio Bartolomeo, chiuse il libro che stava leggendo, si stirò, sbadigliò e disse: / - Luisa, non ti vai a vestire? / - Subito, amore. / E rimase seduta al tavolo, intenta a leggere il Diario di Noticias. Era ancora in vestaglia. Al di sotto dello scollo ampio e abbandonato si intravedeva la camicia di seta azzurra. I capelli biondi, schiacciati in riccioli piatti sulla nuca, denunciavano la pressione del cuscino; era ancora calda di sonno e d'amore, superbamente pigra nel calore del mattino domenicale. Teneva un gomito appoggiato al tavolo, accanto alla tazza vuota della colazione e si accarezzava il lobo bianchissimo dell'orecchio con un movimento lento e sensuale delle dita. (QUEIROZ, 1966, 19).

Trata-se duma versão evidentemente muito menos casta e a personagem de Luísa apresenta-se-nos aqui em toda a sua sensualidade (calda di sonno e d'amore (...) superbamente pigra (...) un movimento lento e sensuale delle dita). Sob este ponto de vista, o segundo exemplo é ainda mais esclarecedor. No capítulo VII, Eça de Queirós descreve nestes termos um dos encontros entre Basílio e Luísa no «Paraíso»:

Tinham tirado os pratos da cama; e sentada à beira do leito, os seus pèzinhos calçados numa meia cor-de-rosa pendiam, agitavam-se, enquanto um pouco dobrada sobre si, os cotovelos sobre o regaço, a cabecinha de lado, tinha em toda a sua pessoa a graça lânguida de uma pomba fatigada. / Bazilio achava-a irresistível: quem diria que uma burguesinha podia ter tanto chique, tanta queda? Ajoelhou-se, tomou-lhe os pèzinhos entre as mãos e beijou-lhos; depois, dizendo muito mal das ligas «tão feias, com fecho de metal», beijoulhe respeitosamente os joelhos; e então fez-lhe baixinho um 
pedido. Ela corou, sorriu, dizia: - Não! Não! - E quando saiu do seu delírio tapou o rosto com as mãos, toda escarlate, murmurou repreensivamente. / - Oh Bazilio! / Ele torcia o bigode, muito satisfeito. Ensinara-lhe uma sensação nova: tinha-a na mão!. (QUEIROZ, 1878, 230).

Também, neste caso, não há nada de muito significativo nas traduções de Marchiori e Crippa ${ }^{8}$. Pelo contrário, La cugina apresenta aos leitores uma situação que nada tem a ver com o texto queirosiano mas que é absolutamente coerente com o sensualismo exacerbado da apresentação inicial de Luisa:

Il primo giorno, Luisa era arrivata da lui pallida come una morta, con il nome del marito sulle labbra ad ogni istante. Si era sentita male appena entrata e non si era neanche guardata intorno, nel gioiello di rifugio che si era sforzato di trovare per lei. Basilio ne aveva provata tanta pietà, tanta tenerezza, da pentirsi di averla sedotta. Non l'avrebbe potuta portare con sé né lo desiderava. Aveva minato un equilibrio matrimoniale per avere un mese di gioia. Deciso a fare di quello il loro primo ed ultimo incontro, l'aveva blandita e l'aveva voluta avere un'unica volta prima di lasciarla per sempre. Fra le sue braccia Luisa si era trasformata. Il torpore disperato era diventato una passionalità violenta, avida. Basilio aveva avuto l'impressione di essere lui a darsi e che Luisa gli suggesse la vita. Ed era così, sempre, con un crescendo spasmodico di sensualità che rasentava la lussuria. Se il piacere fisico aumentava, diventava snervante, se a questo si univa, da parte di Basilio, il gusto malsano di insegnare a Luisa pratiche e meccanismi lascivi cui ella si abbandonava singhiozzando per risorgerne più stremata ma più viva, i rimorsi di Basilio tacevano e l'amore spariva. Vedeva la cugina come una viziosa insoddisfatta del rapporto coniugale. Un'isterica che aveva bisogno di un amante e parlava d'amore da romanzo per trovare una giustificazione. (QUEIROZ, 1966, 68-69). 
Evidentemente na passagem d'O Primo Basílio a La cugina a obra de Eça sofre um processo de erotização, podendo quase dizer-se que tudo neste texto é sexo, chegando amiúde a produzir efeitos de involuntária comicidade: assim, o conselheiro Acácio, nesta versão italiana, está intensamente apaixonado por Luísa ${ }^{9}$, Giuliana padece de voyeurismo ${ }^{10}$ e a travessa de tartaruga de Luísa que, no romance de Eça, a criada chantagista encontra ao pé do divã depois duma visita do sedutor é aqui substituída por "un indumento molto intimo di Luisa. Un indumento che ci si toglie solo per farsi il bagno o per andare a letto... possibilmente con un amante" (Queiroz, 1966, 64).

Por isso, ao fim deste processo de tradução, um romance realista de forte crítica social como é $O$ Primo Basílio transforma-se em La cugina, um romance de paixão, com laivos vagamente pornográficos, onde a pulsão adulterina ganha uma dimensão absolutamente totalizadora; fora dela, de facto, não há nada, a transgressão é uma condição absoluta e, portanto, já não é preciso que haja, como em Eça, causas sociais para a motivar. Esta é, aliás, a razão pela qual em La cugina o adultério de Luísa se justifica unicamente através de causas patológicas, um tumor ao cérebro e o abuso de medicamente para aliviar a dor de cabeça ${ }^{11}$.

A trivialização, portanto, acaba por subverter a ideologia e atraiçoar a poética queirosiana: o romance nesta versão italiana deixa de ser um instrumento para destruir as falsas instituições burguesas do Portugal Constitucional e desaparece completamente o registo irónico, inviável para um produto paraliterário que não admite a possibilidade duma dupla chave de leitura para as suas rígidas personagens. $\mathrm{O}$ resultado final desta operação faz com que La cugina seja muito mais a apoteose do sentimento do que a anatomia dum carácter. Precisamente o contrário do que pretendia fazer o autor escrevendo o romance... ${ }^{12}$

Continua sem resposta a pergunta que já várias vezes ecoou ao longo deste texto: porque é que alguém fez isto? Ou, dito por outras palavras, “(...) a che cosa serve questo bene immateriale che è la letteratura?” (Eco, 8) Não arrisco uma resposta, mas uma 
operação como esta levada a cabo com os "romances diabólicos" parece sugerir que a literatura - quando diabolicamente manipulada - serve sobretudo a vender livros... Contudo, considerar $L a$ cugina simplesmente uma ilegítima e degradante apropriação dum clássico parece-me pouco estimulante e muito apaziguador. Não existindo espaços culturais reciprocamente impermeáveis, é preciso aceitarmos a existência no polissistema literário duma relação dinâmica entre o centro e as margens que contra esse mesmo centro reagem. Aceitar, em suma, a hipótese proposta por Roger Chartier de que os leitores populares não entram em contacto somente com os autores duma literatura popular especificamente criada para eles. Textos e livros também no século XX (e eu até diria sobretudo nos séculos XX e XXI) circulam livremente na totalidade do mundo social e, como sugere o especialista francês, o autêntico desafio é "spostare l'attenzione verso gli usi contrapposti degli stessi generi e, anche se le forme editoriali si rivolgono a pubblici distinti, delle stesse opere" (324).

Mesmo na análise duma obra de pouco interesse como La cugina, a questão fundamental continua a ser a da abordagem popular ao texto literário, sem nunca esquecer que novos leitores produzem sempre novos textos e novas formas geram inevitavelmente novos significados.

\section{Notas}

1. E. Guerra da Cal, Lengua y estilo de Eça de Queiroz, Apéndice, Bibliografia queirociana sistemática y anotada, tomo I, Coimbra, Acta Universitatis Conimbrigensis, 1975. No Apparato bibliografico que integra La corrispondenza di Fradique Mendes, Roberto Vecchi e Vincenzo Russo concordam - como de resto também faz Mariagrazia Russo no apêndice do seu artigo Note traduttologiche queirosiane - com a proposta de Guerra da Cal. Guia Boni refere esta informação bibliográfica, mas não indica uma data de publicação, preferindo limitar-se a um mais prudente "sem data". (Boni, 487). 
2. Devo ao Dr. Adriano Rosellini, Director da Fondazione Rosellini per la Letteratura Popolare, as informações bibliográficas que me permitiram reconstruir a atividade editorial de Ennio Mancini.

3. Veja-se a lista dos autores e das obras publicadas na coleção transcrita no apêndice deste artigo.

4. "Novità si registrano indubbiamente nella produzione di titoli, che dal '56 al '60 ha un incremento del 43,4 per cento (il più alto del dopoguerra), e nel mercato, che dal '57 al '65 vede più che raddoppiarsi e quasi triplicarsi rispettivamente il numero delle famiglie in cui si leggono libri e le relative spese, nel quadro di un generale incremento delle spese per il cinema, giornali e periodici." (Ferretti, 160).

5. "Questa nostra nuova collana è intitolata ai «diabolici». Chi sono «i diabolici»? Perché vengono definiti tali? Bisogna dire anzitutto che la storia dell'arte rigurgita di «diabolici». Caravaggio, il primo grande pittore realista, fu chiamato «maledetto». Villon, il maestro della poesia francese, era un brigante. Cellini, l'enorme cesellatore del Rinascimento italiano, era un avventuriero. Tutti i più grandi geni, tutti i maggiori artisti, furono sempre, in qualche modo, "diabolici». Ed ecco, di conseguenza, le grida allo scandalo, ecco le opere rivelatrici messe alla gogna, ecco i processi, le persecuzioni, che la maggioranza dei grandi artisti hanno subito. In alcuni casi, solo il tempo ha potuto dar ragione ai «diabolici». Solo il tempo, ha potuto portarli sul piedistallo che loro spettava. Ma il tempo, in questa opera di salvazione, ha anche sovente impallido gli affreschi, scalfito $i$ monumenti, rendendoli confusi, a volte non accettabili dagli uomini moderni così come stavano. Nostro compito sarà di agevolarne la diffusione, restaurando gli originali, rendendoli comprensibili e facili da seguire a tutti. Le opere letterarie più celebri e più bistrattate dai contemporanei per la loro pretesa corruzione o oscenità (e che invece scoprivano spesso, proprio sotto la denuncia di certi costumi, una vera moralità), saranno da noi riportate alla luce, modernizzate, colorate un'altra volta, in modo che il pubblico d'oggi possa leggerle agevolmente, nella sua lingua di ogni giorno. E $i$ nostri autori saranno tutti i grandi classici troppo spesso dimenticati nella polvere di qualche biblioteca pubblica, o sacrificati in edizioni antiche, ormai illegibili." (Sade, 3-4).

6. "Era para os lados de Arroios, adiante do Largo de Santa Bárbara: lembrava-se vagamente que havia ali uma correnteza de casas velhas... [...] era num terceiro andar - quem sabe como seria dentro? Lembrava-lhe um romance de Paulo Féval em que o herói, poeta e duque, forra de cetins e tapeçarias o interior de uma choça; encontra ali a sua amante; os que passam, vendo aquele casebre arruinado, 
dão um pensamento compassivo à miséria que decerto o habita - enquanto dentro, muito secretamente, as flores se esfolham nos vasos de Sèvres e os pés nus pisam Gobelins veneráveis! Conhecia o gosto de Bazilio - e o «Paraíso» decerto era como no romance de Paulo Féval" (Queiroz, 1878, 195).

7. "Le mani di Giuliana gli carezzarono il torace, vogliose, impudiche. Antonio sapeva che alle beghine compresse succedeva sempre così. Due soldi per cominciare e dieci per smettere. In questo caso, però, i dieci soldi li avrebbe dati lei. E lui avrebbe smesso" (Queiroz, 1966, 16).

8. "Avevano tolto i piatti dal letto; e seduta sulla sponda, $i$ suoi piedini velati dalle calze rosa, pendevano, si agitavano, mentre, un po' piegata su se stessa, coi gomiti sul grembo, la testa da una parte, aveva in tutta la sua persona la grazia languida di una colomba stanca. Basilio la trovava irresistibile: chi avrebbe detto che una borghesuccia potesse avere tanta eleganza, tanto brio? Si inginocchiò le prese i piedini tra le mani, glieli baciò; poi criticando le giarrettiere "cosi brutte, con fermagli di metallo", le baciò rispettosamente le ginocchia; e poi le rivolse a bassa voce una preghiera. Ella arrossì, sorrise disse: «No! No!». E quando si risvegliò dal suo delirio si coprì il volto con le mani, tutta rossa, mormorò in tono di rimprovero: "Oh! Basilio!» Egli si arricciava i baffi molto soddisfatto. Le aveva insegnato una sensazione nuova. Luisa era nelle sue mani!" (Queiroz, 1952, 198)

"Avevano tolto i piatti dal letto ed ella era seduta sulla sponda. I suoi piedini, velati dalle calze rosa, pendevano, si muovevano. Era un poco ripiegata su se stessa, i gomiti sul grembo, la testa inclinata. In tutta la sua persona era la grazia languida di una colomba affaticata. Basilio la trovava irresistibile: chi avrebbe detto che una borghesuccia potesse essere tanto chic, tanto briosa? Si inginocchiò, le prese i piccoli piedi fra le mani glieli baciò; poi, parlando tanto male delle giarrettiere "così brutte, con i fermagli di metallo", le baciò rispettosamente le ginocchia. Allora, sottovoce, le fece una domanda. Lei arrossi, sorrise, diceva: - No, no! - Quando uscì dal suo delirio si coprì il volto con le mani, tutta rossa, mormorando in tono di rimprovero: - Oh, Basilio. Basilio si arricciava $i$ baffi, molto soddisfatto. Le aveva insegnato un nuovo piacere: la teneva nelle sue mani." (Queiroz, 1952, 205-206)

9. “(...) il consigliere aveva occhi solo per Luisa [...] La passione incelabile dell'austero consigliere per Luisa erano argomento perenne dei loro scherzi. [...] Ma intanto avevano ancora una notte, lo dicevano i loro [de Giorgio e Luisa] occhi, con tanta intensità che Accaccio dovette asciugarsi il cranio lucido di sudore" (Queiroz, 1966, 28-29). 
10. "Un amore che Giuliana conosceva bene. Spesso la notte li spiava attraverso il buco della serratura, esaltandosi per ciò che riusciva a sentire o a vedere e ancor di più per ciò che le sfuggiva." Ibidem, $p$. 27. "Non poteva sapere, il fedele amico di famiglia, che la fedele domestica passava buona parte delle nottate con l'occhio attaccato alla serratura della camera dei padroni" (Queiroz, 1966, 56).

11. "Si era convinto, perché voleva convincersi, che se Luisa aveva mancato in qualche modo, la colpa non era stata sua. Il tumore aveva premuto sui centri nervosi. Con un male di quel genere non poteva essere stata responsabile delle sue azioni" (Queiroz, 1966, 104).

12. Além disso, por incrível que pareça, a livre redução publicada na Itália em 1966 apresenta alguma afinidade com a tradução, feita com intenção moralizadora, que Mary Jane Serrano publicou, em 1889, nos Estados Unidos - mutilando absurdamente a obra e dando ao romance o título de Dragoon's Teeth. Tal como a erotização do texto levada ao cabo na Itália, também o propósito ético de Serrano, de facto, adultera a obra: "O tradutor inglês do Primo Basílio" escrevia um Eça bastante perplexo numa carta de 1890, "cortou-lhe todas as cenas em que os amantes se encontram, em geral, suprimiu o adultério!” (Queiroz, 2008, 26) O resultado final é obviamente diferente mas o objectivo dos dois manipuladores é o mesmo: construir uma versão do romance não necessariamente adequada ao texto original mas aceitável para o público alvo.

\section{Referências}

Boni, Guia. “A Fortuna Italiana de Eça de Queirós.” Congresso de Estudos Queirosianos. IV Encontro Internacional de Queirosianos. Coimbra: Almedina, 2002. 479-489.

Cal, Ernesto Guerra. "Lengua y Estilo de Eça de Queiroz." Bibliografia Queirociana Sistemática y Anotada, Tomo I. Coimbra: Acta Universitatis Conimbrigensis, 1975. 
Chartier, Roger. "Letture e Lettori Popolari dal Rinascimento al Settecento." Cavallo, Guglielmo. Storia Della Lettura. Roma-Bari: Laterza, 2009. 317-335.

Costa, Jaime Raposo. Autori Portoghesi Tradotti ed Editi in Italia. Narrativa Poesia Saggistica (1898 - 1998). Roma: Ambasciata del Portogallo, 1999. 31-35.

Conrieri, Davide. J. M. Eça de Queiroz. Racconti, Milano: BUR, 2000.

Couégnas, Daniel. Paraletteratura. Firenze: La Nuova Italia, 1997.

Delille, Karl. "Os inícios da recepção de Eça na Alemanha." Congresso de Estudos Queirosianos. IV Encontro Internacional de Queirosianos. Coimbra: Almedina, 2002. 191-200.

Di Munno, Amina. "A fortuna de Eça de Queirós em Itália no decorrer de um século." Queirosiana. Estudos sobre Eça de Queirós e a sua Geração, Vol. 7/8. 1995. 23-29.

. "Introduzione, traduzione e note." Queiroz, J. M. Eça de. Racconti. Milano: BUR, 2000.

Eco, Umberto. "Su alcune funzioni della letteratura." Sulla letteratura. Milano: Bompiani, 2002. 7-22.

Ferretti, Gian Carlo. Storia dell'editoria letteraria in Italia. 1945-2003. Torino: Einaudi, 2004.

Flaubert, Gustave. Madame Bovary. Paris: Michel Lévy frères, 1857.

Fontane, Theodor. Cécile. Berlim: Auflage, 1976. . Effi Briest. Berlim: GmbH, 1986. . L'adultera. Berlim: Dtv, 1998. 
Kelsh, Helen. "O Primo Basílio no Mundo Anglo-Saxónico." Congresso de Estudos Queirosianos. IV Encontro Internacional de Queirosianos. Coimbra: Almedina, 2002. 491-502.

Mancini, Ennio. I Romanzi Diabolici. Leonia: Edizioni KKK, 1966.

Nunes, Manuela. "Algumas considerações sobre as traduções alemãs de O Primo Basílio." Congresso de Estudos Queirosianos. IV Encontro Internacional de Queirosianos. Coimbra: Almedina, 2002. 633-646.

Queirós, J. M. Eça de. O Primo Basílio. Lisboa: Livros do Brasil, 1878.

. Il cugino Basilio. Milano: Mondadori, 1952.

. Il cugino Basilio. Milano: Rizzoli, 1952.

. La cugina. Roma: Grandi Edizioni Internazionali, 1966.

. Correspondência. Org. Matos, A. Campos. Lisboa: Caminho, 2008.

Ragone, Giovanni. "L'editoria in Italia. Passato e presente." L'editoria in Italia. Storia e Scenari per il XXI Secolo. Napoli, Liguori: 2005.

Russo, Mariagrazia, "Note traduttologiche queirosiane." Tra centro e periferia. In-torno alla lingua portoghese: problemi di diffusione e traduzione. Viterbo: Sette Città, 2007. 127-145.

Sade, A. "Nota dell'editore." Il vizio e la virtù, Vol 9, No. 16. 1963. 3-4

Tolstoi, Leon. Anna Karenina. Moscou, The Russian Messenger: 1878.

Vecchi, Roberto. \& Russo, Vincenzo. J. M. Eça de Queirós, La corrispondenza di Fradique Mendes. Reggio Emilia: Diabasis, 2009.

Recebido em: 08/09/2014

Aceito em: 10/11/2014 


\section{APÊNDICE}

\section{I romanzi diabolici (1963-1967)}

Na impossibilidade de recolher todos os livros publicados na coleção, a lista das obras aparece incompleta. Quando possível, indica-se o título original da obra, o seu ano de publicação e, eventualmente, o verdadeiro nome do autor. Alguns nomes devem provavelmente considerar-se pseudónimos de autores italianos.

\section{3}

1. James Hogg, L'anima perversa [The private memoirs and confessions of a Justified Sinner, 1824];

2.

3. Nathaniel Hawthorne, Il satiro della notte [The marble faun: or the romance of Monte Beni, 1859]

4. Robert Louis Stevenson, Il club delle tentazioni [The suicide $c l u b, 1878]$

5. Pierre-Alexis Ponson du Terrail, Le ardenti [Les ardentes]

6. Octave Mirbeau, I peccati di Celestina [Le journal d'une femme de chambre, 1900]

7. Jules Barbey, La peccatrice pura [Les diaboliques, 1874]

8. Honoré de Balzac, La sensitiva [Splendeurs et miséres des courtisanes, 1847]

9. Alphonse de Sade, La casta e l'impudica [Nouvelle Justine ou les malheurs de la vertu, 1791] 


\section{4}

10. Jacques d'Epinot, Madame Satana [Gli studi di Huysmans e Cronistoria del processo di Gilles de Rais]

11. Charles Philippe, La cagna [Bubù de Montparnasse, 1901]

12. George G. Byron, Il don Giovanni [Don Juan, 1824]

13. Fëdor Dostoevskij, Passione morbosa [Igrok, 1866]

14. Auguste Mathias[Villiers de L'Isle-Adam], Furia bianca [Le convive de dernières fêtes, in Contes cruels, 1883]

15. Alexandre Dumas, La donna di Cagliostro [Joseph Balsamo, 1848]

16. Pierre Laclos, Le amicizie pericolose [Les liaisons dangereuses, 1782]

17. Émile Zola, Lo scannatoio [L'assommoir, 1877]

18. Oscar Wilde, Il vizio che brucia [The picture of Dorian Gray, 1891]

19. Émile Gaboriau, L'amante diabolica [Le crime d'Orcival, 1867]

20. Honoré de Balzac, La pelle viva [La peau de chagrin, 1831]

21. Bram Stoker, Voluttà infernale [Dracula, 1897]

22. Allan Carrie, Moglie di tutti

23. Jacques Cazotte, Le notti di Satana [Le diable amoureux, 1772]

24. Franz Silberman, Lucrezia Borgia (la sanguinaria);

25. Pierre Forquin, L'insidia [Le procès du diable, 1962];

26. Soeren Kierkegaard, Diario di un seduttore [Forfoererens dagbog, 1843]

\section{5}

27. Claude Seignolle, Le notti oscene [Le bahut noir in Histoires Maléfiques, 1965]

28. Robert Bloch, Il marchio del satiro [More nightmares, 1961]

29. Andrea de Nerciat, La fogna [Félicia ou mes fredaines, 1782]

30. William Thackeray, Moglie in vendita [Men's wives, 1852] 
31. Franz Silberman, Gli sporchi "Cenci”;

32. William Thackeray, La vergogna [The memoirs of Barry Lyndon, 1844]

33. Andrew Recman, Il fuoco tra le mie braccia [Lady in the dark] 34. Arthur Lubin, Un tipo cosi... [Reap the wild wind]

35. Gene Sothern, Letto caldo [The unguarded hour]

36. Jean Murelli, Le due notti [Des faces blêmes, 1965]

37. Glen Wilcox, [Girl of fury]

38. Franz Silberman, La lama del boia;

39. Robert Louis Stevenson, La camera accanto [The Master of Ballantrae. A Winter's tale, 1889]

40. Ruth Hussey, Nuda come la notte [The beginning or the end]

41. Peggy Lund, La pelle aspra [Something to live for]

42. Roger Brinton, La belva nel letto [Men in her life]

43. Ruth Hussey, La mia carne freme [Remember the night]

44. Karin Ralston, Corpo senza volto [Of human hearts]

\section{6}

45. Lars Hanson, Il fuoco dentro [Trapped by ghost]

46. Lew Gaynor, Carne inquieta [Magnificent obsession]

47. Erle Kenton, L'anima a nudo [Lost angel]

48. Kay Francis, Poco a poco... [Time ouf of mind]

49. Sonnie Hale, Questo mio corpo [Ride the man down]

50. Daphne Skyros, La sposa bella [That night]

51. Lew Gaynor, La "pupa" allegra [Written on the wind]

52. Ralph Merker, Attimo su attimo [Mine owne executioner]

53. Claude Bresson, La notte del rogo [Les copains de Rouen]

54. Yves Dassin, La calda bestia [You can't get away with murder]

55. Lew Gaynor, La "mente" sexy

56. J. M. Eça de Queiroz, La cugina [O primo Basílio, 1878]

57. Claude Bresson, Choc della follia [La fin du jour]

58. Tay Brent, Sorte nuda [Beyond the forest]

59. Aldo Marinelli, Eva contro Eva 
60. Aldrich Monasky, Sangue impuro [Borisav Stankovič, Necista Krv, 1910]

\section{7}

61. Glen Wilcox, la strega d'oro [The golden witch]

62. Ugo Palermo, Vita a due

63. Sacha Lopez, L'uomo e la bestia [La cogida y la muerte]

64. Dean Foster, La bionda di fronte [The window of the other side]

65. Sonnie Hale, La donna bianca [The man from down under]

66. Ugo Palermo, La fiamma viva

67. Martin Gabel, La notte di Eva [Devil between us]

68. Giorgio Drigo, Fuoco "Beat"

69. Erich Hansen, L'eroe di carta [Fritz Wöss, Hunde wollt ihr ewig Leben, 1959]

70. Kay Greer, Il primo istinto [They won't believe me]

71. Claude Bresson, Quelli del "clan" [La femme du "clan"]

72. Marco Loy, Goccia a goccia

73. Samuel Evergood, La coda del diavolo [The plunderers]

74. Ralph Merker, Un pugno di droga [All this and heaven too] 